\title{
Nanostructured Tungsten Oxide-Poly(3,4-ethylenedioxythiophene):Poly(styrenesulfonate) Hybrid Films: Synthesis, Electrochromic Response, and Durability Characteristics
}

\author{
M. Deepa, ${ }^{a, z}$ A. K. Srivastava, ${ }^{a}$ K. N. Sood, ${ }^{a}$ and A. V. Murugan ${ }^{b}$ \\ ${ }^{a}$ National Physical Laboratory, New Delhi 110012, India \\ ${ }^{b}$ Department of Mechanical Engineering, Texas Materials Institute, University of Texas at Austin, \\ Austin, Texas 78712, USA
}

\begin{abstract}
Nanostructured hybrid thin films of the system tungsten oxide-poly(3,4-ethylenedioxythiophene):poly(styrenesulfonate) ( $\mathrm{WO}_{3}$-PEDOT:PSS) were synthesized by first forming a tungsten-oxide layer by surfactant-assisted electrochemical method followed by deposition of a PEDOT:PSS layer. The hybrid-film formation is primarily based on coulombic interactions between the surface hydroxyl groups of tungsten oxide and the positively charged centers on the polymer backbone; this has been confirmed by electron microscopy and X-ray diffraction. High-resolution transmission electron microscopy reveals that the tungsten-oxide host with a monoclinic unit cell resides along with the amorphous domains of PEDOT:PSS. The hybrid film, being a dual electrochrome, exhibits a much larger coloring efficiency $\left(227 \mathrm{~cm}^{2} \mathrm{C}^{-1}\right.$ at $\left.600 \mathrm{~nm}\right)$, a higher redox activity (larger currents for ion ingress and egress are obtained within the same potential range), and, most importantly, a superior electrochemical cycling stability when compared to the neat polymer film. While the pristine polymer film lifts off irrevocably from the substrate upon 3000 cycles of coloring and bleaching, the hybrid film sustains about 5000 cycles, albeit with some changes in the nanoparticulate morphology, elemental composition, and development of some new artifacts on the film surface.
\end{abstract} (C) 2008 The Electrochemical Society. [DOI: 10.1149/1.2975388] All rights reserved.

Manuscript submitted April 28, 2008; revised manuscript received August 1, 2008. Published September 22, 2008.

The integration of organic and inorganic materials has aroused much interest in the scientific community for the use of hybrid organic-inorganic materials for catalysis, chiral synthesis, and enhancing electronic conductivity and electro-optical properties. ${ }^{1,2}$ To this end, this report describes a bilayer deposition of two different materials, an n-type semiconductor oxide, tungsten oxide $\left(\mathrm{WO}_{3}\right)$, and a p-type semiconductor, polymer (PEDOT:PSS), to yield a hybrid film and how its structure and composition influences the electrochemical and optical response and chemical stability of the film generated thereof. Since the discovery of electrochromism in $\mathrm{WO}_{3}$ by Deb, ${ }^{3}$ this oxide has been extensively investigated and has drawn considerable attention because of its application in electrochromic cells like smart windows, high-contrast displays, antiglare rearview mirrors, and so forth. ${ }^{4-6}$ PEDOT:PSS is one of the most widely studied electroactive polymers to date because of its excellent film forming ability, high conductivity, and high contrast ratio. ${ }^{7-9} \mathrm{We}$ found that the polymer forms a well-adherent uniform layer when deposited onto the $\mathrm{WO}_{3}$ film, which indicates a strong affinity between the inorganic and organic species. The hybrid film offers the potential of realizing practical improvements of charge-transfer quanta through the bilayer/electrolyte interface and its reversibility as well. Furthermore, in the ever-growing field of solid-state electrochemical devices, the limited understanding of charge-transfer phenomena at the electrode-electrolyte interface is often a factor restricting operational lifetimes.

In an approach to address these issues, in the past, PEDOT has been functionalized or grown in the form of nanotubes or nanowires in order to produce fast-switching films without sacrificing its high color contrast. ${ }^{10-12}$ But, preserving the cycling durability without compromising the optical modulation of the films continues to pose a formidable challenge. Reynolds et al. ${ }^{13}$ observed that electrochromic devices based on derivatized PEDOT films retained about $60 \%$ of their original transmittance modulation after cycling the same 10,000 times between the clear and dark states. Hammond ${ }^{14}$ and Cutler ${ }^{15}$ have, in separate reports, investigated the sequential layerby-layer adsorption of oppositely charged polyelectrolytes, and this method of generating multilayer thin films since then has been widely exploited as a means to coat large areas in a controlled manner, useful for the production of electrochromic devices. Because a

żE-mail: m_deepa@mail.nplindia.ernet.in prerequisite for using any material for this application is a large operational lifetime and low-cost production, promising candidates are transition-metal oxides; of the lot, tungsten oxide is most exciting due to good reversibility of the color-bleach process over repeated cycling. ${ }^{5}$ To meet this objective, herein we have done electrochemical synthesis of tungsten oxide in the presence of a polymeric surfactant, followed by the adsorption of PEDOT:PSS polymer onto the metal-oxide surface. The advantages of surfactantmediated electrosynthesis of $\mathrm{WO}_{3}$ have been discussed in our earlier reports. ${ }^{16,17}$

Although $\mathrm{V}_{2} \mathrm{O}_{5}$-PEDOT and polyoxometallate-PEDOT hybrid films have been investigated in the past ${ }^{18,19}$ and the photoinduced tuning of electric conductivity of PEDOT:PSS-TiO ${ }_{2}$ composite films has been demonstrated, ${ }^{20}$ the $\mathrm{WO}_{3}$-PEDOT system remains largely unexplored to date. We have previously ${ }^{21-23}$ studied the dependence of microstructure and electrochromic properties of pristine PEDOT films on the nature of dopant ions in the growing medium. The irreversible electrochemical cycling behavior of the electropolymerized PEDOT films in our earlier reports ${ }^{21,23}$ provided the stimulus for developing a material with good cycling durability and consistent optical response. The method employed here offers an extremely simple alternative means to form organic-inorganic hybrid films with high scalability. The coexistence of an amorphous PEDOT:PSS phase with nanocrystalline domains of monoclinic tungsten oxide is achieved through this strategy, wherein the advantages of a large optical contrast in the photopic region and rapidswitching kinetics offered by PEDOT:PSS and good redox cycling durability of $\mathrm{WO}_{3}$ are synergistically combined to yield films with an improved and optimized electrochromic performance. The merits of this bilayer deposit of $\mathrm{WO}_{3}$ and PEDOT:PSS have been exemplified by comparing the microstructure, composition, optical properties, and electrochemical cycling stability of the neat oxide or polymer with that of the hybrid material.

\section{Experimental}

Materials and film deposition.- Tungsten-metal powder (13.0 g, $<100 \mu$ ) was dissolved in $120 \mathrm{~mL}$ of $\mathrm{H}_{2} \mathrm{O}_{2}(30 \%$, Qualigens) at $\sim 50^{\circ} \mathrm{C}$. The filtered solution was refluxed at $\sim 55$ to $60^{\circ} \mathrm{C}$ for $6 \mathrm{~h}$ for decomposition of excess peroxide, followed by the addition of $40 \mathrm{~mL}$ of isopropanol (GR, Merck) and $10 \mathrm{~mL}$ of the surfactant polyethylene glycol 400 (Merck). The solution was filtered again for removal of any particulates, and potentiostatic elec- 
trodeposition was performed in a three-electrode electrochemical cell with a platinum sheet (Aldrich, $4 \times 4 \mathrm{~cm}$ ) as the auxiliary electrode, $\mathrm{SnO}_{2}: \mathrm{F}$-coated glass substrate as the working electrode, and $\mathrm{Ag} / \mathrm{AgCl} / \mathrm{KCl}$ as the reference electrode. The $\mathrm{SnO}_{2}: \mathrm{F}$-coated glass substrates procured from Pilkington were $4 \mathrm{~mm}$ thick and possessed a sheet resistance of $14-16 \Omega / \square$. The substrates were cleaned in dilute $\mathrm{HCl}$, double-distilled water, and acetone prior to use. The primary electrode (deposition area: $\sim 4 \times 3 \mathrm{~cm}$ ) was subjected to a constant cathodic potential of $-0.45 \mathrm{~V}$ for $15 \mathrm{~min}$ at room temperature. The blue-colored $\mathrm{WO}_{3}$ films were immediately rinsed in a deionized water and ethanol mixture (1:1 volume ratio) and the films bleached completely when dried in air for $2-3 \mathrm{~h}$. The films were annealed at $250^{\circ} \mathrm{C}$ for $2 \mathrm{~h}$ and neat $\mathrm{WO}_{3}$ films were obtained. Baytron $\mathrm{P}$ formulation composed of about $0.8 \%$ sodium poly(styrenesulfonate) and $0.5 \%$ PEDOT by mass was used as received. The $\mathrm{pH}$ of the PEDOT:PSS solution was in the range of $2.5-2.6$ at $25^{\circ} \mathrm{C}$. The Baytron P solution was spin-coated at $1000 \mathrm{rpm}$ for $30 \mathrm{~s}$ over (a) the thermally treated neat tungsten-oxide films mounted on $\mathrm{SnO}_{2}:$ F/glass substrates and (b) on bare $\mathrm{SnO}_{2}: \mathrm{F}$-coated glass as well. The films were heated at $80^{\circ} \mathrm{C}$ for $1 \mathrm{~h}$, and hybrid $\mathrm{WO}_{3}-\mathrm{PEDOT}$ :PSS and neat PEDOT:PSS films were obtained. For transmission electron microscopy (TEM), the hybrid film was deposited on a carbon-coated nickel grid.

Characterization techniques. - X-ray diffraction (XRD) patterns of the films were recorded with a Bruker AXS D8 advance diffractometer using $\mathrm{Cu} \mathrm{K} \alpha(\lambda=1.5406 \AA)$ radiation, and the glancing angle of incidence was fixed at $0.5^{\circ}$. A scanning electron microscope (SEM, LEO 440) was used for studying the surface morphological characteristics of the films, and energy-dispersive X-ray spectroscopy (EDX) plots of the films were recorded on an EDS Oxford Link ISIS 300. High-resolution TEM (HRTEM) studies on the sample were carried out using a TEM FEI-Tecnai $G^{2}$ F30 STWIN, and selected area electron diffraction (SAED) patterns were recorded on a TEM, model JEOL JEM 200 CX operated at $200 \mathrm{kV}$. Fourier transform infrared (FTIR) spectrum in reflectance mode for the hybrid film was recorded with a Perkin Elmer Spectrum BX FTIR spectrophotometer; the angle of incidence was kept at $35^{\circ}$. Absorbance spectra of the hybrid $\mathrm{WO}_{3}$-PEDOT:PSS, neat PEDOT:PSS, and neat $\mathrm{WO}_{3}$ films were recorded in situ in a glass cell in the $300-1100 \mathrm{~nm}$ wavelength range with respect to air in the reference beam in a Perkin-Elmer Lambda 25 spectrophotometer. The films were colored and bleached by application of different dc potentials, and the step time was fixed at $10 \mathrm{~s}$. The charges involved in oxidation and reduction of the films were obtained from the integration of the area under the corresponding $I$ vs $t$ curves, and these values were used for calculating coloring efficiency of the films. Switching time characteristics between the colored and bleached states for the films were recorded by multiple-step chronoamperometry with an indigenously developed microprocessor-controlled setup, which is described in detail in a previous report. ${ }^{24}$ Cyclic voltammetry $(\mathrm{CV})$ for the films was performed with an Omni potentiostat (Cypress Instruments) in a classical three-electrode electrochemical cell within $\pm 1 \mathrm{~V}$, wherein the hybrid $\mathrm{WO}_{3}-\mathrm{PEDOT}$ :PSS or neat PEDOT:PSS or a neat $\mathrm{WO}_{3}$ film acted as the working electrode, $\mathrm{Ag} / \mathrm{AgCl} / \mathrm{KCl}$ was employed as the reference electrode, a Pt rod was used as the auxiliary electrode, and the electrolyte was a $1 \mathrm{M}$ solution of lithium trifluoromethanesulfonate (Aldrich) in propylene carbonate (Merck) (1 $\left.\mathrm{M} \mathrm{LiCF}_{3} \mathrm{SO}_{3}-\mathrm{PC}\right)$.

\section{Results and Discussion}

XRD studies. - The X-ray diffractogram of the neat polymer film in Fig. 1a shows the film to be amorphous, as can be deduced from the featureless nature of the pattern. The pattern of neat $\mathrm{WO}_{3}$ film (Fig. 1b) shows a distinct intense peak at $d=3.65 \AA$ and a few low-intensity peaks at $d=3.11,3.08$, and $2.53 \AA$ corresponding to $200, \overline{1} 12,112$, and $\overline{1} 22$ reflections of monoclinic (m) $\mathrm{WO}_{3}$ in accordance with PDF number 43-1035. For the tungsten oxidePEDOT:PSS hybrid film (Fig. 1c), the main diffraction line of

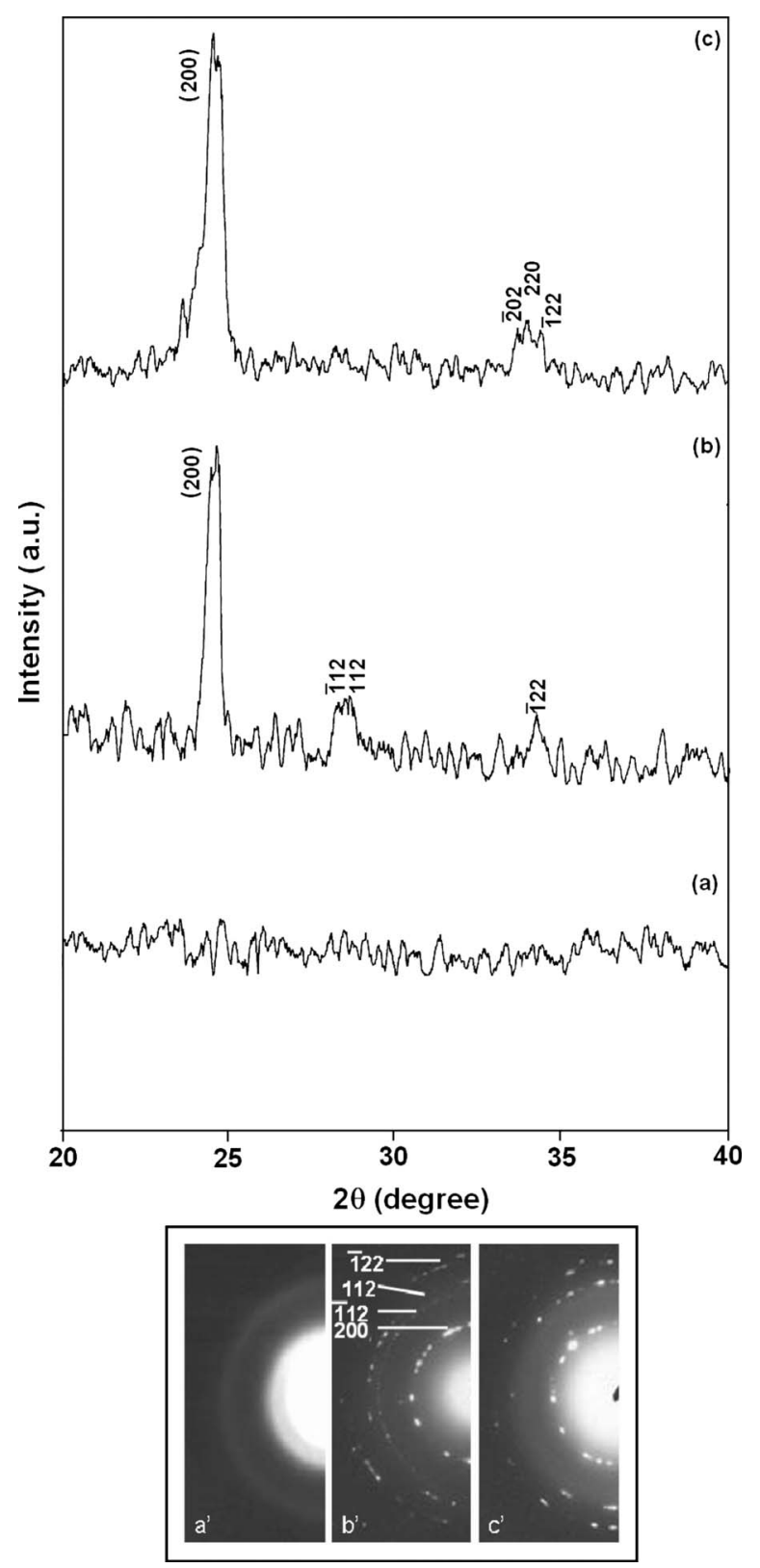

Figure 1. XRD patterns of (a) neat PEDOT:PSS film, (b) neat tungstenoxide film, and (c) $\mathrm{WO}_{3}-\mathrm{PEDOT}$ :PSS hybrid film, recorded at a scan step of $0.02^{\circ} \mathrm{min}^{-1}$, and the corresponding SAED patterns of $\left(\mathrm{a}^{\prime}\right)$ neat PEDOT:PSS film, $\left(b^{\prime}\right)$ neat tungsten-oxide film, and $\left(c^{\prime}\right) \mathrm{WO}_{3}-$ PEDOT:PSS hybrid film.

$\mathrm{m}-\mathrm{WO}_{3}$ at $3.65 \AA$ still exists, but new peaks emerge at 2.65 and $2.61 \AA$, and these can be ascribed to 202 and 220 planes of $\mathrm{m}-\mathrm{WO}_{3}$. These observations reveal that the crystal structure (monoclinic phase) and the preferred orientation of the oxide host along the 200 plane remain unchanged, by deposition of PEDOT:PSS on $\mathrm{WO}_{3}$, but structural modifications do occur along certain crystallographic planes which can be judged on the basis of the disappearance of the less-intense peaks ( $\overline{1} 12$ and 112) of pure $\mathrm{m}-\mathrm{WO}_{3}$ in the pattern of the hybrid film. The crystallite size estimated by Scherrer's formula from the intensity maximum at $d(200)$ is $\sim 18 \mathrm{~nm}$ for the neat $\mathrm{WO}_{3}$ film and $\sim 15 \mathrm{~nm}$ for the hybrid film. For all films under scrutiny, that the peaks are not sharp, but rather broad, shows that these films do have an amorphous component, which is also ratified from the SAED patterns shown in Fig. $1 \mathrm{a}^{\prime}-\mathrm{c}^{\prime}$. The SAED patterns of the pristine polymer film in Fig. 1a' reveal diffuse halo rings typical of the amorphous structure, and the SAED pattern of neat tungsten 


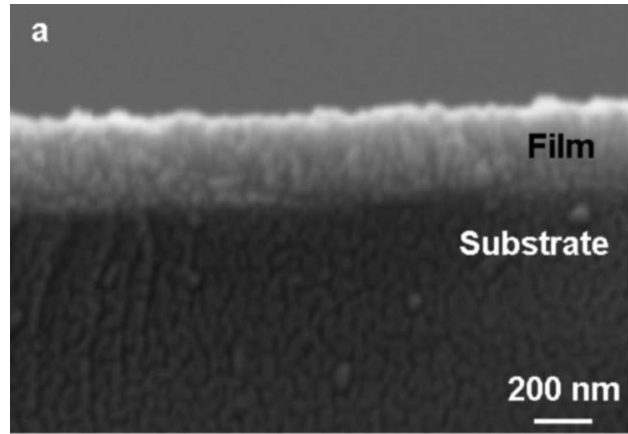

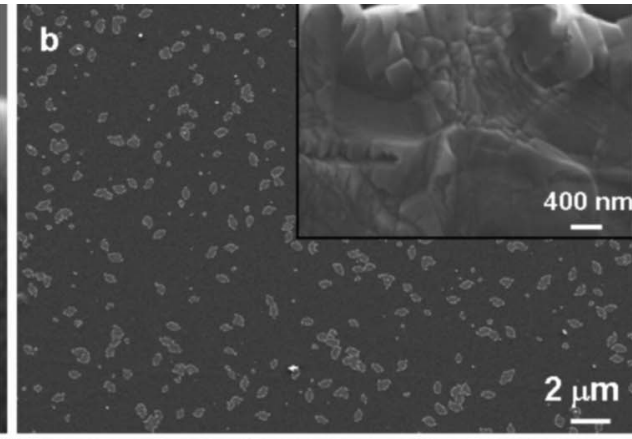

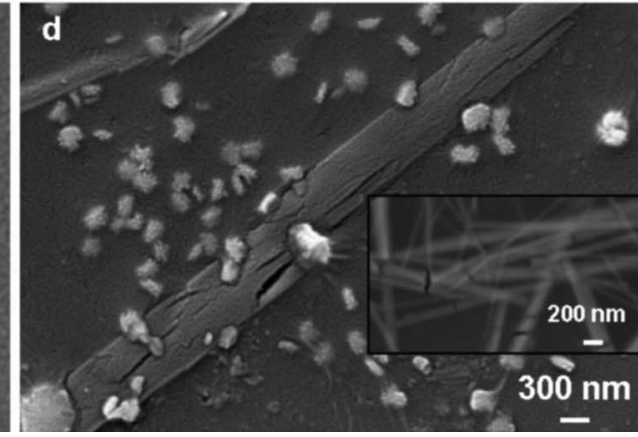

Figure 2. SEM images of a virgin $\mathrm{WO}_{3}$-PEDOT:PSS hybrid film before cycling: (a) cross-sectional view of the $\mathrm{WO}_{3}$-PEDOT:PSS hybrid film showing the uniformity along thickness, (b) lowmagnification image showing the particulate morphology (inset is a magnified view of one such particle), (c) the regular granular-porous morphology of the film, and (d) the granular structure of film, ruptured in certain regions (inset shows evolution of some elongated shapes in the film after the film was subjected to 5000 color-bleach cycles). oxide (Fig. $1 b^{\prime}$ ) shows Debye rings corresponding to 200, 112,112 , and $\overline{1} 22$ planes of $\mathrm{m}-\mathrm{WO}_{3}$ crystal structure. The hybrid film (Fig. $1 \mathrm{c}^{\prime}$ ) shows a composite pattern of halo rings (characteristic of the amorphous structure of the polymer) overlapping with the Debye rings of monoclinic $\mathrm{WO}_{3}$ phase. These evidences confirm the XRD results. It is also noteworthy that the spots corresponding to the $\overline{1} 12$ and 112 planes of $\mathrm{m}-\mathrm{WO}_{3}$ are not seen, and the extra spots observed around the spot corresponding to the $\overline{1} 22$ plane can be associated with the multiple peaks seen around the peak due to 122 reflection in the XRD pattern of the hybrid film (Fig. 1 $\mathrm{c}^{\prime}$ ).

Electron microscopy studies. - The cross-sectional SEM image of the film in Fig. 2a confirms the formation of the hybrid $\mathrm{WO}_{3}$-PEDOT:PSS, as the whole film is visible as a single entity and not as two separate layers along the thickness. The thickness of the film is approximately $380 \mathrm{~nm}$. The film formation can be explained as follows. The clear dispersion of PEDOT:PSS (Fig. 3a) easily percolates through the pores in the $\mathrm{WO}_{3}$ film, and this is further accelerated by the $\mathrm{WO}_{3}$ surface, rich in hydroxyl groups or Bronsted sites (Fig. 3b) ${ }^{25}$ which interact with the positively charged sulfur atoms on the polymer. At this point, a clear distinction needs to be made between the voids present in the crystal structure of $\mathrm{WO}_{3}$ (at the lattice scale) and the pore structure of the film. The structure of monoclinic $\mathrm{WO}_{3}$ is built up from corner/edge-sharing and distorted $\mathrm{WO}_{6}$ octahedra, the unit cell consists of eight such tilted octahedra, and therefore four-membered rings conducive for intercalants are formed. ${ }^{26}$ The schematic in Fig. $3 \mathrm{c}$ shows these interstitial voids; these are easily occupied by the guest ions during coloration, and the rings can even accommodate more than one lithium ion per active site. $^{26,27}$ This ion insertion-extraction capability of tungsten oxide supplements the doping-dedoping process of PEDOT.

The planar surface morphology of the hybrid film reveals it to be constituted by particles embedded in a homogeneous surface (Fig. 2b). A high-magnification image recorded on one of these particles reveals clusters of grains with well-defined facets (inset of Fig. 2b). The high-magnification image of the background in Fig. $2 b$ is shown in Fig. 2c, which reveals the film to be constituted by interconnected

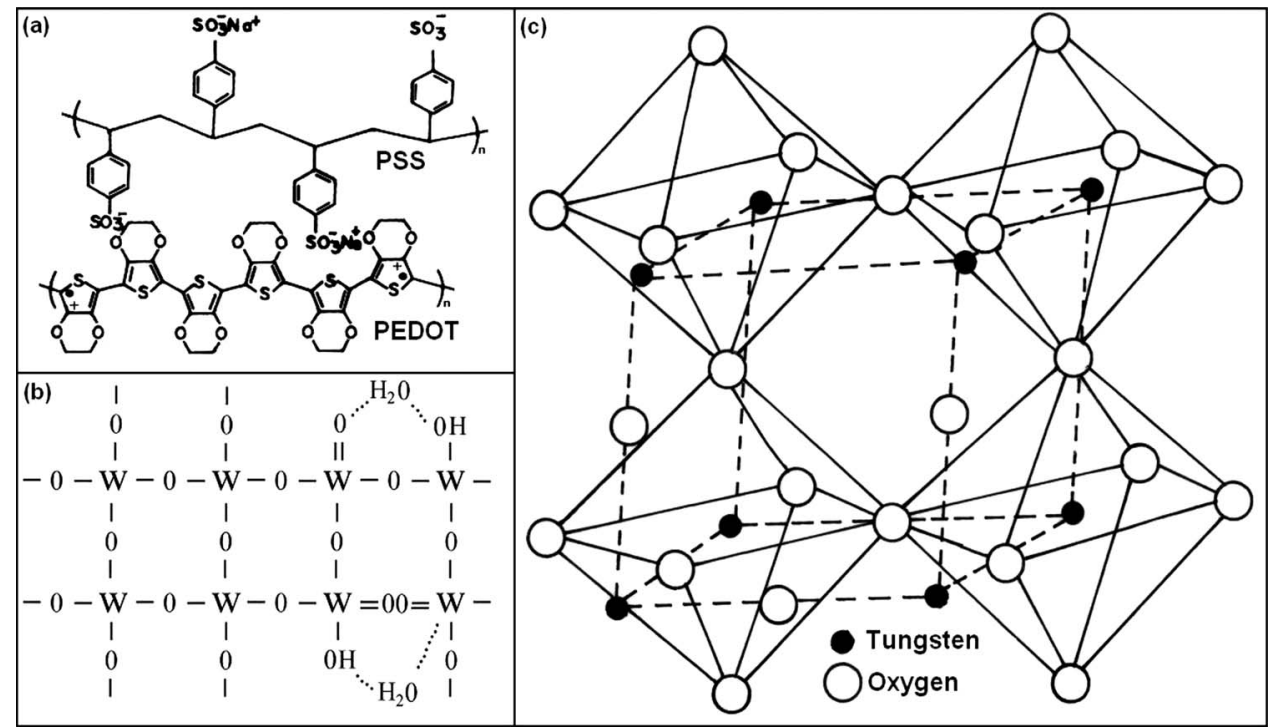

Figure 3. Schematic of (a) PEDOT:PSS, (b) two-dimensional view of tungstenoxygen network in the film, and (c) structure of monoclinic $\mathrm{WO}_{3}$, showing the formation of four-membered voids for guest ion insertion. 


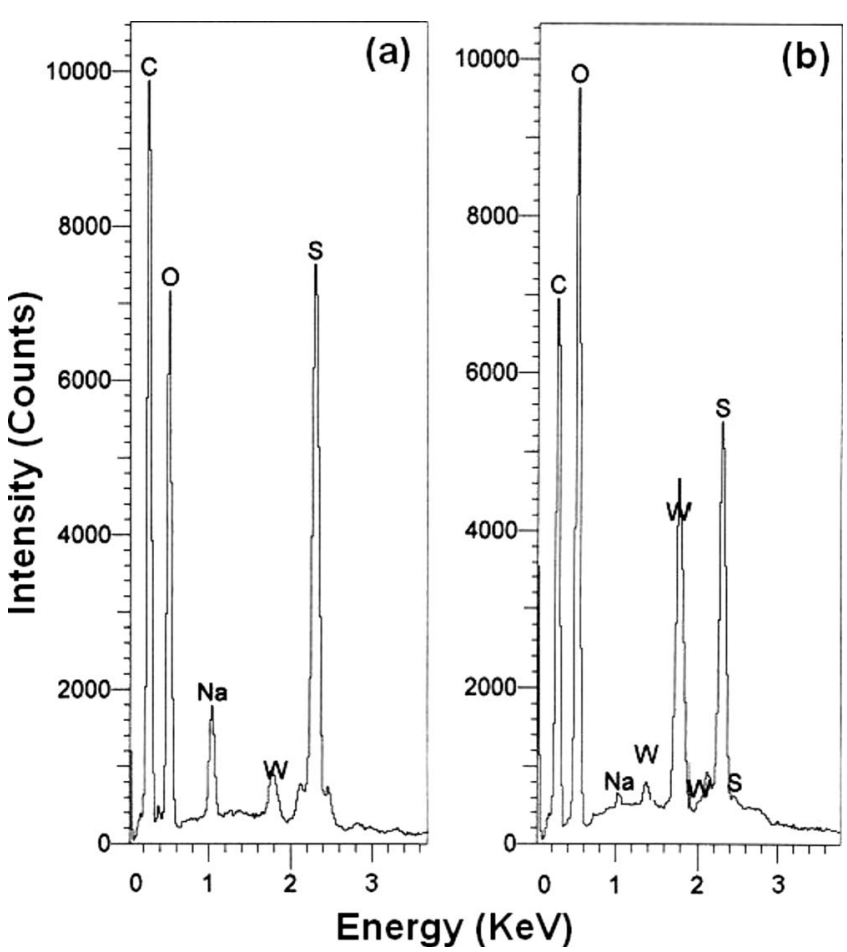

Figure 4. EDX plots of a $\mathrm{WO}_{3}-\mathrm{PEDOT}$ :PSS hybrid film (a) before cycling and (b) after 5000 cycles of coloration and bleaching in a $1 \mathrm{M}$ $\mathrm{LiCF}_{3} \mathrm{SO}_{3}-\mathrm{PC}$ electrolyte.

grains (of $\sim 40$ to $60 \mathrm{~nm}$ dimensions) and pores. The effect of electrochemical cycling in a liquid electrolyte on the microstructure of the hybrid film is shown in Fig. 2d, and how it differs from that of the cycled neat PEDOT:PSS film can be judged from the corresponding micrographs. The hybrid film was colored and bleached 5000 times in a $1 \mathrm{M} \mathrm{LiCF}_{3} \mathrm{SO}_{3}-\mathrm{PC}$ solution under a square-wave $\mathrm{dc}$ potential of $\pm 1.2 \mathrm{~V}$ at a frequency of $0.011 \mathrm{~Hz}$. Cycling of the hybrid film is accompanied by development of new artifacts in certain portions of the film, such as $(i)$ long, rodlike shapes that grow in all possible directions and are misaligned with respect to each other (inset of Fig. 2d) and (ii) aggregation of particles (Fig. 2d). These shapes are also ruptured at some places. Postcycling, a few cracks can be seen on the surface but, by and large, the grain-pore morphology remains unchanged (Fig. 2d). This hints at the robustness of the hybrid structure as, even after 5000 cycles of ion ingress and egress, the structure continues to be receptive toward a color-bleach process. The neat virgin PEDOT:PSS film, as anticipated, has a smooth, homogeneous texture, and no granular, porous structure was perceptible even at high magnifications (micrograph not shown here), which is somewhat typical of amorphous films. The film, however, showed cracks of the order of tens of micrometers after 3000 color-bleach cycles.

EDX spectrum of the hybrid film in Fig. 4a shows the film to be primarily composed of $\mathrm{W}, \mathrm{O}, \mathrm{S}$, and $\mathrm{C}$. The relative atomic composition of the said elements varies from the fresh hybrid film (Fig. 4a) to the cycled one (Fig. 4b). In the pristine hybrid film, the atomic (\%) ratio of sulfur to tungsten is 23.6, whereas, after this film was subjected to 5000 color-bleach cycles, this ratio reduces to 2.74 . This reaffirms that film thinning does occur through slow dissolution in electrolyte upon electrochemical cycling, accelerated by the driving voltage. This depleted sulfur content in the cycled film also confirms that PEDOT:PSS is more susceptible to electrolyte degradation.

TEM image of the $\mathrm{WO}_{3}-\mathrm{PEDOT}$ PSS film in Fig. 5a reveals that the film is porous throughout, and pore diameters are found to be around $1 \mathrm{~nm}$, which accounts for the ability of the film to take up a

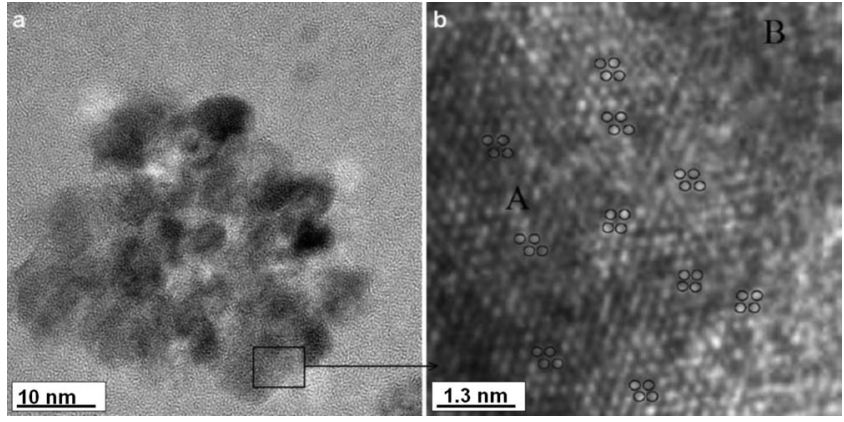

Figure 5. TEM images of the neat $\mathrm{WO}_{3}-\mathrm{PEDOT}$ PSS hybrid film (a) showing the crystalline and amorphous $\mathrm{WO}_{3}$ particles coexistent with an amorphous matrix of PEDOT:PSS and (b) HRTEM image of crystalline $\mathrm{WO}_{3}$ showing the formation of voids from four-membered rings conducive for intercalants in the monoclinic lattice of $\mathrm{WO}_{3}$ : (A) crystalline and (B) amorphous regions.

large number of ions during electrochemical cycling. From the HRTEM image of the film (Fig. 5b), the crystalline portions $\left(\mathrm{WO}_{3}\right.$ crystallites with plane facets and a monoclinic structure constitute region A) can be easily distinguished from the amorphous part $\mathrm{B}$, which comprises of mingling grains with indistinct grain boundaries. The formation of four membered rings conducive for ion insertion and extraction is also evident from Fig. 5b, which is experimental proof for the description provided in the schematic in Fig. 3. The two-dimensional model proposed in Fig. $3 \mathrm{~b}$ shows the crosslinked $\mathrm{W}-\mathrm{O}-\mathrm{W}$ networks and how the $-\mathrm{OH},-\mathrm{OH}_{2}$, and $-\mathrm{O}^{2-}$ link with tungsten in the corner- and edge-sharing array of $\mathrm{WO}_{6}$ octahedra. ${ }^{28}$ The structure of the hybrid film is such that it ensures an optimum electrochromic function. It is also obvious that grains devoid of plane facets in the film (region B) are amorphous, which complies with the XRD and SAED results. Further, Fig. 5b shows that there are no distinct boundaries separating the amorphous grains of $\mathrm{WO}_{3}$ or PEDOT:PSS from the crystalline grains of $\mathrm{WO}_{3}$, and this confirms the coexistence of amorphous (polymer) and crystalline (oxide) phases.

FTIR spectroscopic data analysis. - The FTIR spectrum of the hybrid film in Fig. 6 shows overlapping contributions from PEDOT and tungsten oxide. The bands at 1373, 1230, 1092, and $898 \mathrm{~cm}^{-1}$ are due to $\mathrm{C}_{\beta}-\mathrm{C}_{\beta}$ (intra-ring) stretch, $\mathrm{C}_{\alpha}-\mathrm{C}_{\alpha^{\prime}}$ (inter-ring) stretch $+\mathrm{C}_{\beta}$ bending, $\mathrm{C}-\mathrm{O}-\mathrm{C}$ deformation, and oxyethylene ring deformation modes of PEDOT, respectively. ${ }^{29,30}$ These bands demonstrate the presence of PEDOT chains with $\alpha-\alpha^{\prime}$ coupling. The peaks at

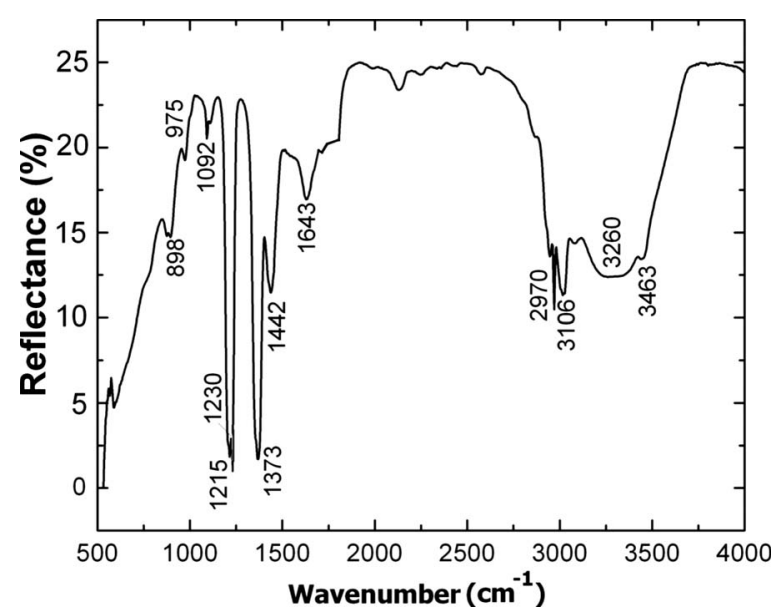

Figure 6. FTIR spectrum of the neat $\mathrm{WO}_{3}-\mathrm{PEDOT}$ :PSS hybrid film recorded in the $500-4000 \mathrm{~cm}^{-1}$ wavenumber region. 


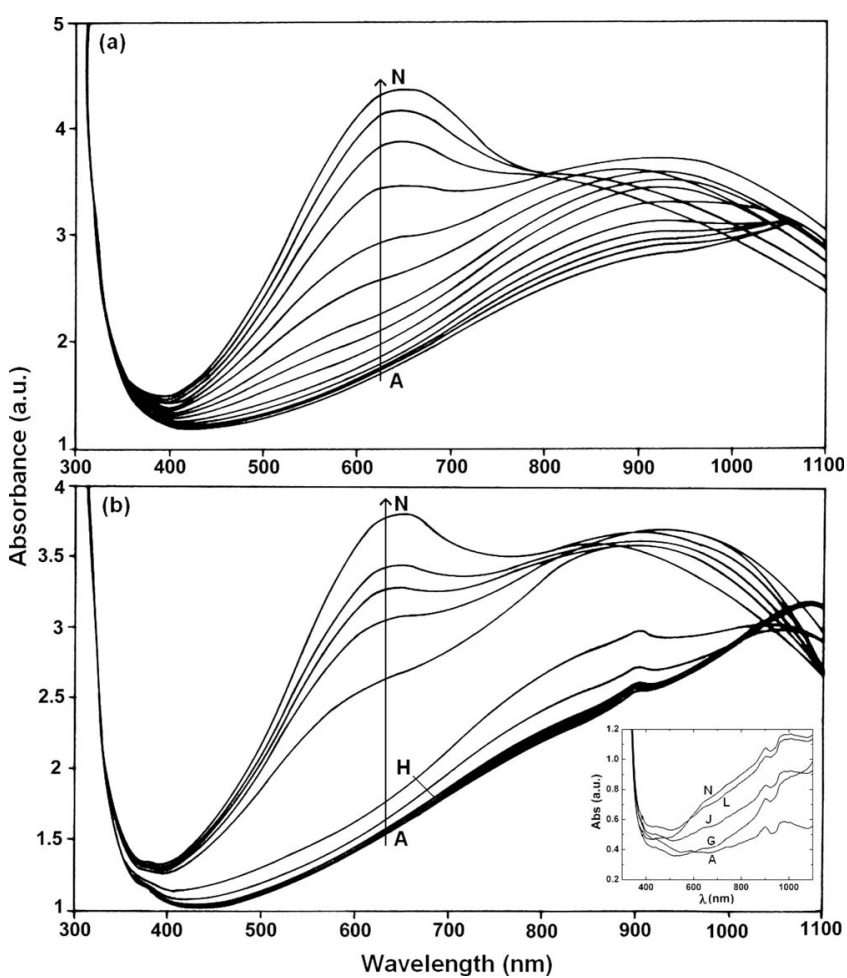

Figure 7. In situ absorbance spectra of (a) the neat $\mathrm{WO}_{3}-\mathrm{PEDOT}$ :PSS hybrid film and (b) neat PEDOT:PSS film (inset shows the absorbance spectra of the neat $\mathrm{WO}_{3}$ film in the $300-1100 \mathrm{~nm}$ wavelength range). Plots were recorded under dc potentials of $(\mathrm{A}):+1.0,(\mathrm{~B})+0.5,(\mathrm{C})-0.1,(\mathrm{D})-0.2$, (E) $-0.3,(\mathrm{~F})-0.4,(\mathrm{G})-0.5,(\mathrm{H})-0.6$, (I) -0.7, (J) -0.8, (K) -0.9, (L) - 1.0,

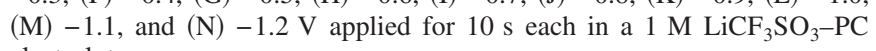
electrolyte.

$\sim 1643$ and $2970 \mathrm{~cm}^{-1}$ are attributable to the in-plane bending mode $\delta\left(\mathrm{H}_{2} \mathrm{O}\right)$ of structural water and $\nu(\mathrm{OH})$ stretching vibration of water molecules structurally bound to the $\mathrm{WO}_{3}$ matrix. ${ }^{26}$ The existence of hydroxyl groups bonded to tungsten can be realized from the $1442 \mathrm{~cm}^{-1}$ band that arises from the $\mathrm{W}-\mathrm{OH} \ldots . \mathrm{OH}_{2}$ groups in $\mathrm{WO}_{3}{ }^{31,32}$ The stretching mode of $\mathrm{S}-\mathrm{O}$ in $-\mathrm{SO}_{3}^{-}$in poly(styrene sulfonate) of PEDOT:PSS also produces a band at $1215 \mathrm{~cm}^{-1}{ }^{33}$ The presence of hydrogen-bonded $\mathrm{W}-\mathrm{OH} \ldots . \mathrm{OH}_{2}$ linkages and $\mathrm{SO}_{3}^{-}$ groups in the film indicates the possibility of coulombic attractive forces to be operative between the hydroxyl groups on $\mathrm{WO}_{3}$ and the positively charged PEDOT backbone and by means of links between the sulfate groups in dopant PSS $^{-}$and tungsten-metal ion.

Absorbance behavior and cycling durability. - In the oxidized state, both PEDOT and $\mathrm{WO}_{3}$ show a weak absorbance in the 350-750 nm (visible region). Due to a much larger absorption coefficient of PEDOT in contrast to that of $\mathrm{WO}_{3}$, the absorption spectrum of the hybrid film is dominated by the characteristic absorptions of the polymer rather than $\mathrm{WO}_{3}$, as can be judged from Fig. 7a. Typical plots depicting the change in the absorption of neat tungsten oxide under potential extrema of $(+1.0 \mathrm{~V}$ : fully bleached and $-1.2 \mathrm{~V}$ : pale blue) and at intermediate reducing voltages of $-0.5,-0.8$, and $-1.0 \mathrm{~V}$ are shown in the inset of Fig. $7 \mathrm{~b}$. The change in absorbance with applied potential is rather small as compared to that shown by neat PEDOT:PSS (Fig. 7b). Surprisingly, no measurable change in absorbance was detected between -0.1 and $-0.5 \mathrm{~V}$ for the pure polymer film, and higher potentials were required to overcome the interfacial resistance at the $\mathrm{SnO}_{2}$ :F/PEDOT:PSS interface to induce coloration. Contrary to this, for the hybrid film, absorbance showed a steady increase as the applied potential was raised from -0.1 to $-1.2 \mathrm{~V}$ in steps of $0.1 \mathrm{~V}$, which suggests that the conducting substrate-hybrid film contact is

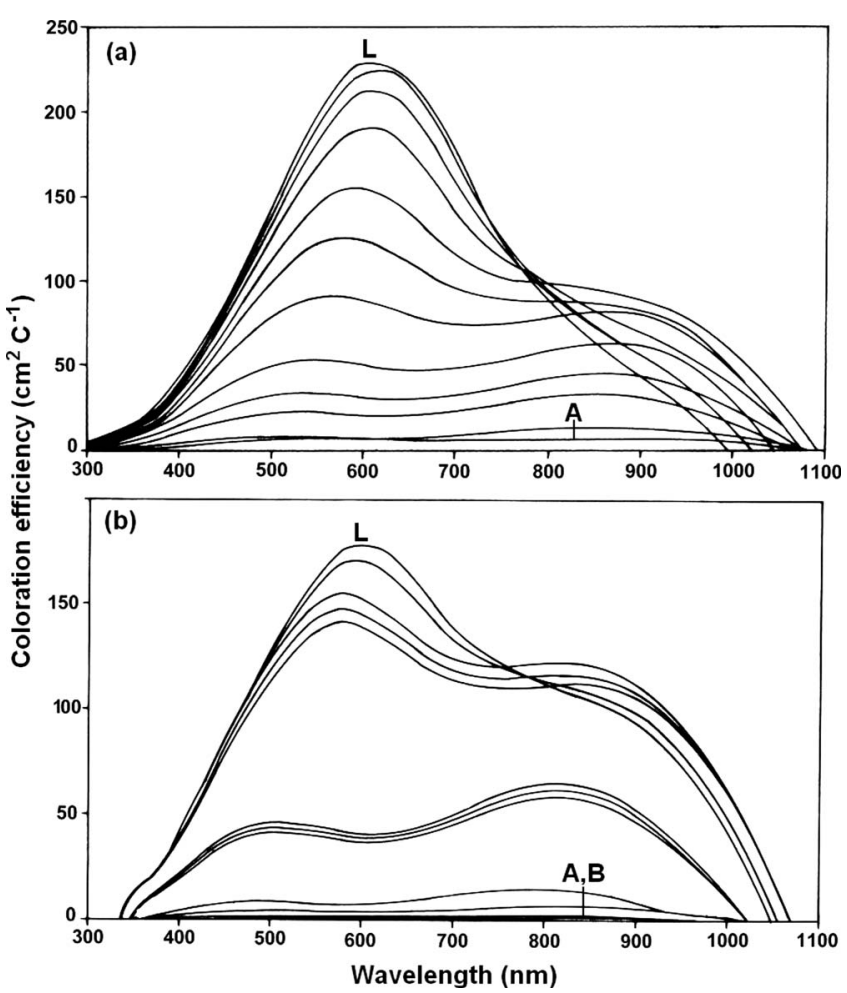

Figure 8. Coloration efficiency plots of (a) the neat $\mathrm{WO}_{3}-\mathrm{PEDOT}$ :PSS hybrid film and (b) neat PEDOT:PSS film under dc potentials of (A) -0.1 , (B) -0.2 , (C) -0.3 , (D) -0.4, (E) -0.5, (F) -0.6, (G) -0.7, (H) -0.8, (I) -0.9, (J) $-1.0,(\mathrm{~K})-1.1$, and $(\mathrm{L})-1.2 \mathrm{~V}$ in a $1 \mathrm{M} \mathrm{LiCF}_{3} \mathrm{SO}_{3}-\mathrm{PC}$ electrolyte; the optical state under $+1.0 \mathrm{~V}$ has been taken as a reference.

nearly ohmic. The spectra of both the hybrid film (Fig. 7a) and the neat PEDOT:PSS film (Fig. 7b) show the progressive depletion of the $\pi-\pi^{*}$ transition with oxidation. This transition gives way to an absorbance at higher wavelengths $(\sim 900 \mathrm{~nm})$, associated with the charge-carrier states after full $\pi-\pi^{*}$ depletion, and this absorption appears to be more pronounced in neat PEDOT:PSS as compared to the hybrid film. While the pure polymer film shows a huge leap in absorbance when the applied voltage is changed from -0.8 to $-0.9 \mathrm{~V}$, for the hybrid film the change is gradual in the entire potential range under consideration. The coloring efficiency as a function of wavelength for the films is shown in Fig. 8. For the highly reduced state (in both hybrid and pure polymer films), coloration efficiency shows a maximum at $\sim 600 \mathrm{~nm}$, and this wavelength of maximum efficiency blueshifts to $521 \mathrm{~nm}$ in the oxidized form (the peak is almost nonexistent at this stage).

The coloring-efficiency response resembles the absorbance behavior; the magnitude of coloring efficiency is larger for the hybrid film (Fig. 8a) as compared to that of neat PEDOT:PSS (Fig. 8b). For the latter film, coloring-efficiency plots show two maxima, the first one at $\sim 595 \mathrm{~nm}$, which downshifts to $\sim 500 \mathrm{~nm}$, and the second one in the range of $800-850 \mathrm{~nm}$, with a lower magnitude than the first one (in the highly reduced states); this trend reverses with increasing oxidation. The visible coloration efficiency is larger for the hybrid film due to its better ability to take up a larger number of adsorbates or ions for the same value of external bias as compared to the pristine PEDOT:PSS film. The enhancement in cation loading is due to the porous microstructure of the hybrid film, which improves the accessibility of the electrolyte with the active sites in the film, and therefore a larger absorbance change is realized for the same value of applied bias. Further, the coloring efficiency of the hybrid film also takes into account the algebraic sum of change in optical densities of PEDOT:PSS and $\mathrm{WO}_{3}$. Pure tungsten oxide derived by sol-gel or an electrochemical processing generally shows a coloring 
efficiency of $60-80 \mathrm{~cm}^{2} \mathrm{C}^{-1}$ in the visible region, ${ }^{16}$ which is relatively low when compared with that of PEDOT or its analogues. For the hybrid film, a coloring-efficiency maximum of $227 \mathrm{~cm}^{2} \mathrm{C}^{-1}$ $(\lambda \approx 600 \mathrm{~nm})$ is observed under an applied square-wave potential of $-1.2 \mathrm{~V}(10 \mathrm{~s})$ and $+1.0 \mathrm{~V}(10 \mathrm{~s})$. In this report, under the said values of square-wave potential, the highest optical density change corresponding to the switching between the two extreme states, and therefore the largest coloring efficiency, was observed under these conditions. Under similar conditions, the pure PEDOT:PSS film shows a $\eta=177 \mathrm{~cm}^{2} \mathrm{C}^{-1}(\lambda \approx 595 \mathrm{~nm})$. A composite coloration efficiency of $183 \mathrm{~cm}^{2} \mathrm{C}^{-1}$ was obtained for PEDOT, corresponding to a $95 \%$ transmittance change of the full optical switch in the visible region. ${ }^{34}$ Lin et al. observed a coloring efficiency of $206 \mathrm{~cm}^{2} \mathrm{C}^{-1}$ for a PEDOT film grown in a conventional liquid electrolyte. ${ }^{35}$ For PEDOT films doped by camphorsulfonate ions visà-vis electrolpolymerization, ${ }^{23}$ we observed a $\eta_{\max }=132 \mathrm{~cm}^{2} \mathrm{C}^{-1}$ $(\lambda \approx 465 \mathrm{~nm}$ ). Thus, the coloring efficiency obtained for the hybrid film is either higher or comparable to the reported values of coloring efficiency for PEDOT.

The hybrid film and the pure polymer films were switched from an oxidized state to a reduced state by applying alternate square potentials of +1.2 and $-1.2 \mathrm{~V}$ at a monochromatic wavelength of $632.8 \mathrm{~nm}$ and at a frequency of $0.016 \mathrm{~Hz}$, and the response plots are shown in Fig. 9 and 10. The area of the films was $\sim 4 \times 1.2 \mathrm{~cm}$. Coloring time of the neat PEDOT:PSS film, defined as time required by the film to acquire $50 \%$ of its full response, is $1.4 \mathrm{~s}$, and bleaching occurs in $1.5 \mathrm{~s}$ (Fig. 10a). For the hybrid film, $1.9 \mathrm{~s}$ are required for coloration, and bleaching takes place in $0.7 \mathrm{~s}$ (Fig. 9a). Color kinetics is slower for the hybrid film, due to a barrier at the hybrid film electrode-liquid electrolyte interface. Due to the propensity of tungsten oxide to offer resistance to the exchange current density at this interface, this barrier is formed. ${ }^{36}$ This barrier is absent for the pure polymer film at the ion-injection interface, and therefore coloration is fast. A larger optical contrast is realized for the hybrid film, due to its enhanced capacity to insert and extract cations. But, bleaching kinetics is faster for the hybrid film, as during bleaching, both the back electromotive force (emf) and the applied potential act in the same direction, so a greater driving force is available for ions to diffuse out of the film, under the same value of applied bias. ${ }^{36}$ For the hybrid film, optical response was also recorded under a frequency of $\sim 1 \mathrm{~Hz}$ (Fig. 9b). Although steady colored and bleached states could not be attained, color and bleach times of 1.0 and $0.5 \mathrm{~s}$ (averaged over five cycles) were calculated for the (total) optical change shown in Fig. 9b. The pure polymer film did not show a quantifiable response at this frequency, perhaps due to the resistive barrier at the $\mathrm{SnO}_{2}$ :F/PEDOT:PSS interface. For electropolymerized PEDOT films, switching time for an approximately $40 \%$ transmittance change was reported to be $2.2 \mathrm{~s} .{ }^{37}$ As anticipated, after cycling the hybrid film 5000 times in the liquid electrolyte, optical modulation reduces to almost half of its original value, and switching times also increase. The hybrid-cycled film now colors in $2.0 \mathrm{~s}$ and bleaches in $2.7 \mathrm{~s}$ (Fig. 9c). The PEDOT:PSS film lifted off from the substrate approximately a few cycles after 3000 cycles of coloring and bleaching, which is also evident from the corresponding micrograph. Before the film succumbed to degradation, coloring and bleaching times were 24.8 and $2.0 \mathrm{~s}$, respectively (Fig. 10b). Thereafter, no optical response could be detected in the film upon application of voltage.

Redox behavior and electrochemical cycling. - Cyclic voltammograms recorded at different scan speeds of 5, 10, 20, 50, and $100 \mathrm{mV} \mathrm{s}^{-1}$ for the hybrid film and the pure PEDOT:PSS film are shown in Fig. 11. For the pure polymer film (Fig. 11c), in the curve recorded at $5 \mathrm{mV} \mathrm{s}^{-1}$ a broad oxidation peak is observed at $+0.07 \mathrm{~V}$, and this peak shifts to more-positive potentials with increasing scan rate. The peak is followed by a flat current plateau and a cathodic peak at $-0.6 \mathrm{~V}$ in the reverse scan. Such a quasireversible faradaic capacitive response is more dominant at scan speeds $\leqslant 20 \mathrm{mV} \mathrm{s}^{-1}$. The $\mathrm{CV}$ profile changes drastically from the
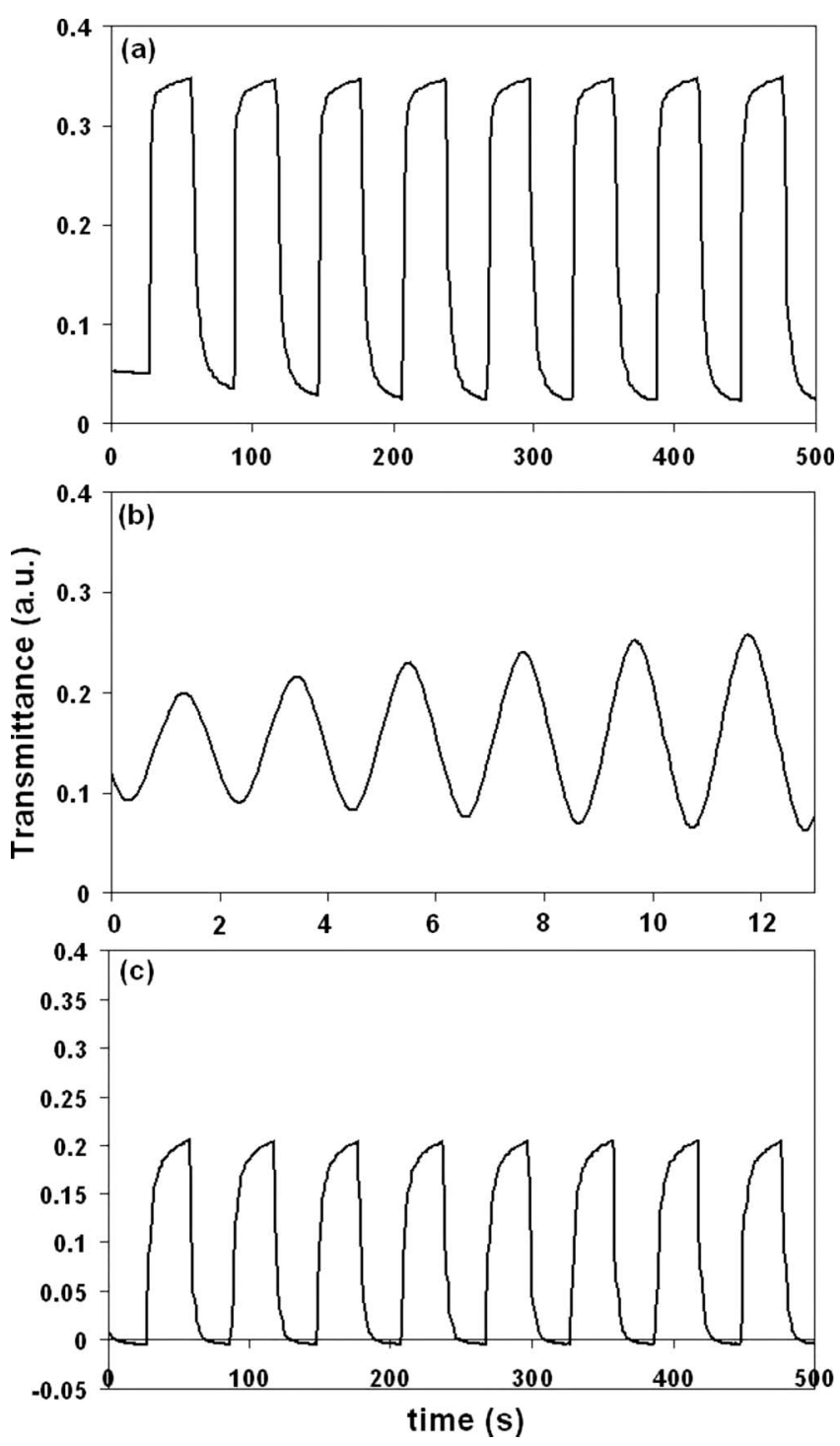

Figure 9. Variation of transmittance at a monochromatic wavelength of $632.8 \mathrm{~nm}$ as a function of time for the neat $\mathrm{WO}_{3}$-PEDOT:PSS hybrid film under a square-wave dc potential of $\pm 1.2 \mathrm{~V}$ for different step times of (a) 30 and (b) $1.1 \mathrm{~s}$ in the initial cycles and (c) after 5000 color-bleach cycles with a step time of $30 \mathrm{~s}$ in a $1 \mathrm{M} \mathrm{LiCF}_{3} \mathrm{SO}_{3}-\mathrm{PC}$ electrolyte.

polymer film to the hybrid film. The oxidation peak for pure polymer observed at $+0.50 \mathrm{~V}$ in the voltammogram recorded at $100 \mathrm{mV} \mathrm{s}^{-1}$ (Fig. 11c) shifts to $+0.11 \mathrm{~V}$ (Fig. 11a) in the case of the hybrid film at the same scan rate. The two limiting mechanisms for charge compensation during oxidation of the hybrid material are departure of the cations and electrons from the film and arrival of the anions from the electrolyte. In tungsten oxide, during oxidation the back emf acts in the same direction as applied potential, ${ }^{36}$ and therefore a larger driving force is available for charge transfer at the hybrid film/electrolyte interface in comparison to the pure polymer film for the same value of applied bias. Further, in the hybrid film, electron movement occurs through tungsten oxide tethered to the $\mathrm{SnO}_{2}: \mathrm{F}$ coating; the barrier to electron transport is nonresistive. So, the electroneutrality condition is achieved at lower oxidation potentials. This barrier is resistive in the case of the PEDOT:PSS film, as it was observed earlier that no optical response could be measured for this film at high frequency, and as this is a spin-coated polymer material, it has poorer adherence with the inorganic substrate. Therefore, higher oxidation potentials are required for the abovedescribed charge transfer in the PEDOT:PSS film. The redox activ- 


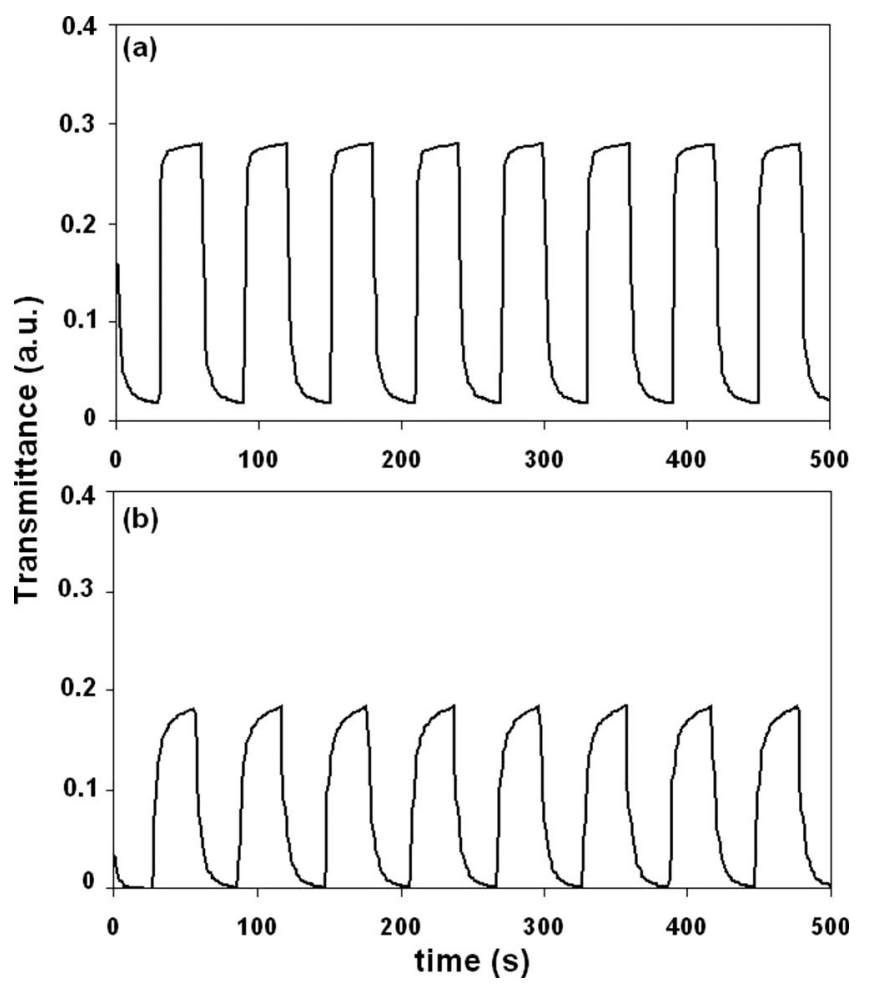

Figure 10. Variation of transmittance at a monochromatic wavelength of $632.8 \mathrm{~nm}$ as a function of time for the neat PEDOT:PSS film under a squarewave dc potential of $\pm 1.2 \mathrm{~V}$ : (a) in the initial cycles and (b) after 5000 color-bleach cycles under a constant step time of $30 \mathrm{~s}$ in a $1 \mathrm{M}$ $\mathrm{LiCF}_{3} \mathrm{SO}_{3}-\mathrm{PC}$ electrolyte.

ity of PEDOT:PSS is not lost on going from the pure polymer to the hybrid material; this can be easily deduced by comparing the area under the voltammograms for the hybrid film with that of pure tungsten oxide, recorded at different scan rates. The areas are much larger for the hybrid film in both cathodic and anodic branches.

The $\mathrm{CV}$ response therefore carries signatures of both PEDOT and $\mathrm{WO}_{3}$, and the associated redox processes can be described as follows

$$
\begin{aligned}
& (\mathrm{PEDOT})^{x+}(\mathrm{PSS})^{x-}+y \mathrm{CF}_{3} \mathrm{SO}_{3}^{-} \\
& \leftrightarrows \mathrm{PEDOT}^{(x+y)+}: x \mathrm{PSS}^{-}: y \mathrm{CF}_{3} \mathrm{SO}_{3}^{-}+y \mathrm{e}^{-} \\
& \mathrm{WO}_{3}+y \mathrm{Li}^{+}+y \mathrm{e}^{-} \leftrightarrows \mathrm{Li}_{y} \mathrm{WO}_{3}
\end{aligned}
$$

While PEDOT is blue in the dedoped state, tungsten oxide is blue when metal (lithium) tungsten bronze is formed; because the two processes complement each other, a deep blue color is attained under cathodic potentials. But, the anodic process of PEDOT:PSS shifts to cathodic potentials in the hybrid film. When the scan rate is lowered from 100 to $5 \mathrm{mV} \mathrm{s}^{-1}$, the position of the anodic peak for the hybrid film shifts to cathodic potentials, i.e., from +0.11 to $-0.15 \mathrm{~V}$, and the position of the reduction peak shifts from -0.12 to $-0.5 \mathrm{~V}$. This implies that when available reaction times increase, higher reduction potentials are required for cation insertion and anion extraction, and oxidation potentials for the reverse process shift to negative potentials. A similar shift of the anodic peak was observed by Randriamahazka et al. for PEDOT films cycled in an ionic liquid. ${ }^{38}$ The diffusion coefficient (determined using oxidationpeak current dependence on scan rate by the Randles-Sevcik equation) for anion insertion was $7.05 \times 10^{-11} \mathrm{~cm}^{2} \mathrm{~s}^{-1}$, and it increased to $1.74 \times 10^{-10} \mathrm{~cm}^{2} \mathrm{~s}^{-1}$ when the scan rate was decreased from 100 to $5 \mathrm{mV} \mathrm{s}^{-1}$ for the hybrid film. At lower scan rates, larger $D$ values for both films are responsible for faster ion ingress, and therefore the oxidation process for the material shifts to cathodic potentials. The same holds true for the pure polymer film (the $D$ values are lower by $\sim 10^{-11} \mathrm{~cm}^{2} \mathrm{~s}^{-1}$ than that of the hybrid), and therefore oxidation occurs at lower potentials at lower scan rates.

The influence of cycling on the electrochemical activity of the films is shown in Fig. 11b and d (hybrid and polymer, respectively) when the films were subjected to repetitive cycling at a fixed scan rate of $100 \mathrm{mV} \mathrm{s}^{-1}$. For the polymer film, initially both cathodic and anodic peak current densities increase slightly with cycling; the increase continues until about a hundred cycles, then it drops abruptly to about $0.30 \mathrm{~mA} \mathrm{~cm}^{-2}$ in both anodic and cathodic branches, and finally the currents decrease steadily to $0.09 \mathrm{~mA} \mathrm{~cm}^{-2}$ (anodic) and $0.07 \mathrm{~mA} \mathrm{~cm}^{-2}$ (cathodic), as can be seen from Fig. 11d, at the end of 3000 cycles. The initial enhancement in the peak currents could be attributed to an increasing capability of the film to uptake ions, longer soaking, or accessibility of the electrolyte with the film with cycling; this could be due to some structural reorganization, which is activated when electrolyte anions/cations move in and out. For the hybrid film (Fig. 11b), the anodic peak current density shows a

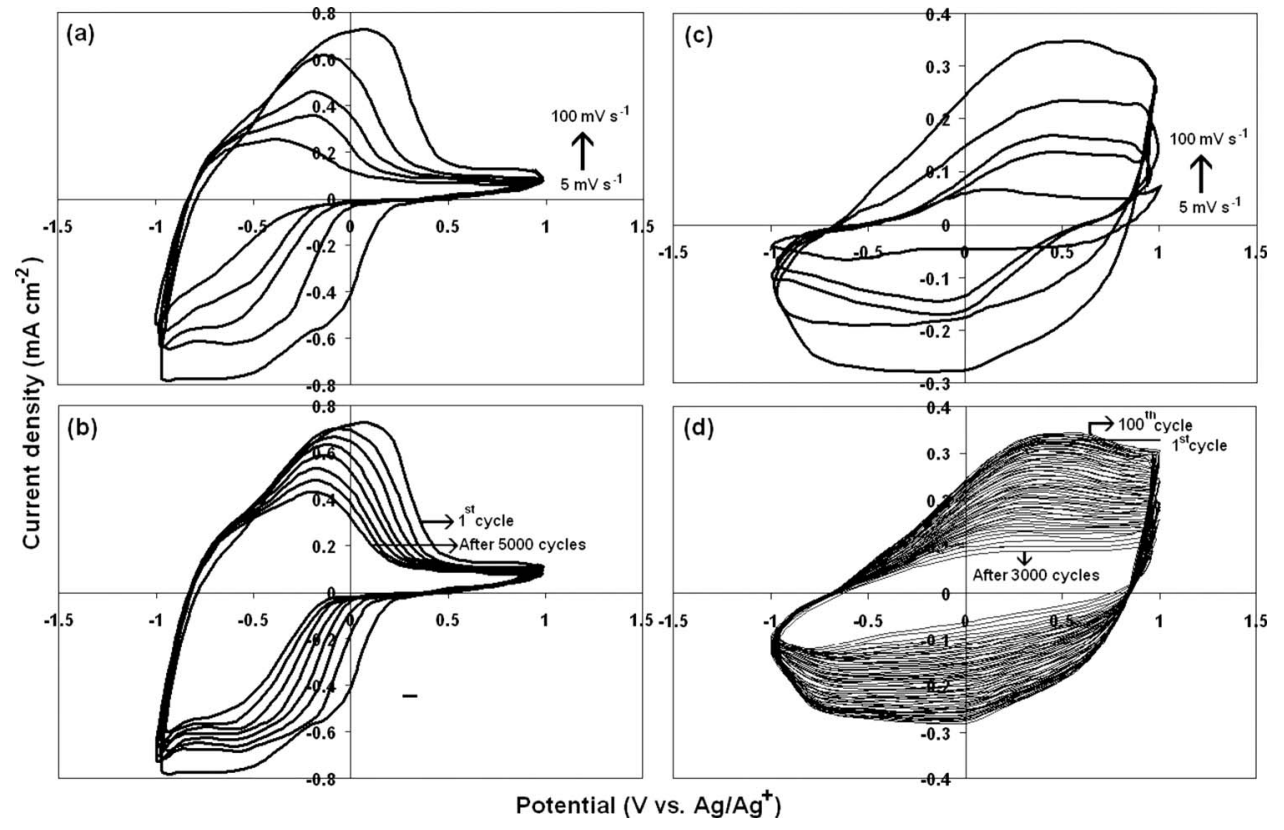

Figure 11. Cyclic voltammograms of (a) neat $\mathrm{WO}_{3}$-PEDOT:PSS hybrid film and (c) a neat PEDOT:PSS film recorded at scan rates of $5,10,20,50$, and $100 \mathrm{mV} \mathrm{s}^{-1}$; (b) plots recorded for the hybrid film: the first cycle and after 10, 100, 1000, 2000, 3000, 4000, and 5000 cycles, and (d) recorded intermittently after every 20 cycles for the neat PEDOT:PSS film during 3000 cycles of coloration and bleaching at a fixed scan rate of $100 \mathrm{mV} \mathrm{s}^{-1}$ in a $1 \mathrm{M} \mathrm{LiCF}_{3} \mathrm{SO}_{3}-\mathrm{PC}$ electrolyte. 
gradual systematic decline from $0.72 \mathrm{~mA} \mathrm{~cm}^{-2}$ (in the first cycle at $+0.11 \mathrm{~V}$ ) to $0.40 \mathrm{~mA} \mathrm{~cm}^{-2}$ (after 5000 cycles at $-0.22 \mathrm{~V}$ ). The corresponding cathodic current density maximum decrease is from -0.76 to $-0.60 \mathrm{~mA} \mathrm{~cm}{ }^{-2}$. With cycling, a gradual shift of anodic peak current densities to cathodic potentials (from +0.11 to $-0.22 \mathrm{~V}$ in hybrid and from +0.52 to $+0.34 \mathrm{~V}$ in neat polymer) was also observed. During cycling, two phenomena occur; the radical cation of PEDOT permanently traps anions during oxidation, and tungsten oxide entraps lithium ions irreversibly during reduction, so a certain fraction of the material becomes increasingly electrochemically inactive with cycling. Second, voltage-driven dissolution of the film in the electrolyte also takes place; although this rate can be minimized (as in the hybrid film here), it cannot be inhibited completely. ${ }^{13}$ These two phenomena are responsible for the loss of redox activity with increasing the number of cycles in both films. But the anodic peak shift is due to the faster decay of the polymer, as EDX results also showed diminished sulfur content as compared to tungsten-oxide content in the cycled hybrid film. So, the oxidation peak shifts to negative potentials, which is typical of $\mathrm{WO}_{3}$. In the future, we intend to carry out electrochemical impedance studies to determine the rate-controlling parameters during oxidation and reduction of the hybrid films.

\section{Conclusions}

Tungsten oxide-PEDOT:PSS hybrid films have been fabricated by a two-step process involving the surfactant-mediated electrodeposition of the $\mathrm{WO}_{3}$ film, followed by deposition of the PEDOT:PSS layer. Electrostatic attraction between the hydroxyl groups on $\mathrm{WO}_{3}$ and the sulfur atoms on the polymer chains associated with a positive charge are responsible for the formation of a hybrid structure wherein facetted nanoparticles of tungsten oxide with a monoclinic lattice coexist with the amorphous phase of the polymer. Cyclic voltammetric plots showed that the electrochemical response of the $\mathrm{WO}_{3}$ film is substantially preserved in the hybrid, but absorbance plots demonstrated that the optical response generated as a function of applied voltage in the visible region is strongly reminiscent of the polymer PEDOT:PSS. The enhanced coloring efficiency and larger electrochemical activity of the hybrid film is a repercussion of the "voids" or four-membered rings in the $\mathrm{WO}_{3}$ lattice and the porous surface morphology that enhance guest ion uptake and the combined abilities of tungsten oxide and PEDOT:PSS to color (blue) under cathodic potentials. The improved adherence of the hybrid film with the inorganic electrode (as compared to the poor bonding of the pristine polymer film with the underlying substrate) is largely responsible for its superior cycling durability, as the film endures 5000 color-bleach cycles without incurring any major loss in optical or redox activity, thereby indicating the practical applicability of these films as cathodes in electrochromic smart windows.

\section{Acknowledgments}

We thank Dr. D. P. Singh for XRD measurements and Dr. Shailesh Sharma for FTIR spectral studies. Professor K. Chattopadhyay (I.I.Sc. Bangalore) is gratefully acknowledged for extending the HRTEM facility. Financial assistance from the Department of Science and Technology (grant no. 91330) is gratefully acknowledged.

\section{References}

1. J. Wang, X. Yu, Y. Li, and Q. Liu, J. Phys. Chem. C, 111, 18073 (2007).

2. E. A. Olvetti, J. H. Kim, D. R. Sadoway, A. Asatekin, and A. M. Mayes, Chem Mater, 18, 2828 (2006)

3. S. K. Deb, Appl. Opt. Suppl., 3, 192 (1969); S. K. Deb, Philos. Mag., 27, 801 (1973).

4. C. G. Granqvist, in Handbook of Inorganic Electrochromic Materials, p. 23, Elsevier, Amsterdam (1995).

5. G. A. Niklasson and C. G. Granqvist, J. Mater. Chem., 17, 127 (2007).

6. P. K. Shen, J. S. Bokhari, and A. C. C. Tseung, J. Electrochem. Soc., 138, 2778 (1991).

7. J. Quyang, C.-W. Chu, F.-C. Chen, Q. Xu, and Y. Yang, Adv. Funct. Mater, 15 203 (2005); A. M. Nardes, M. Kemerink, R. A. J. Janssen, A. M. Bastiaansen, N. M. M. Kiggen, B. M. W. Langeveld, A. J. J. M. van Breeman, and M. M. de Kok, Adv. Mater. (Weinheim, Ger.), 19, 1196 (2007); M. Dobbelin, R. Marcilla, M. Salasmendi, C. P. Gonzalo, P. M. Carrasco, J. A. Pomposo, and D. Mecerreyes, Chem. Mater, 19, 2147 (2007).

8. J. Hwang, F. Amy, and A. Kahn, Org. Electron., 7, 387 (2006).

9. R. R. Smith, A. P. Smith, J. T. Stricker, B. E. Taylor, and M. F. Durstock, Macromolecules, 39, 6071 (2006).

10. S. I. Cho, W. J. Kwon, S.-J. Choi, P. Kim, S.-A. Park, J. Kim, S. J. Son, R. Xiao, S.-H. Kim, and S. B. Lee, Adv. Mater. (Weinheim, Ger.), 17, 171 (2005).

11. J. L. Duvail, P. Retho, S. Garreau, G. Louarn, C. Godon, and S. DemoustierChampagne, Synth. Met., 131, 123 (2002).

12. G. Sonmez, H. Meng, Q. Zhang, and F. Wudl, Adv. Funct. Mater., 17, 726 (2003)

13. S. A. Sapp, G. A. Sotzing, and J. R. Reynolds, Chem. Mater, 10, 2101 (1998).

14. D. M. DeLongchamp, M. Kastantin, and P. T. Hammond, Chem. Mater, 15, 1575 (2003).

15. C. A. Cutler, M. Bouguettaya, T.-S. Kang, and J. R. Reynolds, Macromolecules, 38, 3068 (2005).

16. M. Deepa, A. K. Srivastava, K. N. Sood, and S. A. Agnihotry, Nanotechnology, 17, 2625 (2006); M. Deepa, A. K. Srivastava, and S. A. Agnihotry, Acta Mater, 54, 4583 (2006).

17. M. Deepa, A. K. Srivastava, S. Lauterbach, G. Gupta, S. M. Shivaprasad, and K. N. Sood, Acta Mater, 50, 6095 (2007).

18. A. V. Murugan, C.-W. Kwon, G. Campet, B. B. Kale, A. B. Mandale, S. R. Sainker, C. S. Gopinath, and K. Vijayamohanan, J. Phys. Chem. B, 108, 10736 (2004).

19. L. Adamczyk, P. J. Kulesza, K. Miecznikowski, B. Palys, M. Chojak, and D. Krawczyk, J. Electrochem. Soc., 152, E98 (2005).

20. N. Sakai, G. K. Prasad, Y. Ebina, K. Takada, and T. Sasaki, Chem. Mater, 18, 3596 (2006)

21. M. Deepa, S. Bhandari, M. Arora, and R. Kant, Macromol. Chem. Phys., 209, 137 (2008).

22. S. Ahmad, M. Deepa, and S. Singh, Langmuir, 23, 11430 (2007).

23. S. Bhandari, M. Deepa, S. Singh, G. Gupta, and R. Kant, Electrochim. Acta, 53, 3189 (2007).

24. M. Deepa, A. K. Srivastava, M. Kar, and S. A. Agnihotry, J. Phys. D, 39, 1885 (2006).

25. T. C. Arnoldussen, J. Electrochem. Soc., 128, 117 (1981).

26. M. F. Daniel, B. Desbat, J. C. Lassegues, B. Gerand, and M. Figlarz, J. Solid State Chem., 67, 235 (1987).

27. K. S. Cheng, A. J. Jacobson, and M. S. Whittingham, Solid State Ionics, 5, 355 (1981).

28. J.-H. Choy, Y.-I. Kim, J.-B. Yoon, and S.-H. Choy, J. Mater. Chem., 11, 1506 (2001).

29. C. Li and T. Imae, Macromolecules, 37, 2411 (2004).

30. S. Garreau, G. Louarn, J. P. Buisson, G. Froyer, and S. Lefrant, Macromolecules, 32, 6807 (1999).

31. M. Deepa, A. K. Srivastava, S. N. Sharma, G. Gupta, and S. M. Shivaprasad, Appl. Surf. Sci., 254, 2342 (2007).

32. C. Santato, M. Odziemkopwski, M. Ulmann, and J. Augustynski, J. Am. Chem. Soc., 123, 10639 (2001)

33. D. Han, G. Yang, J. Song, and L. Niu, J. Electroanal. Chem., 602, 24 (2007).

34. C. L. Gaupp, D. M. Welsh, R. D. Rauh, and J. R. Reynolds, Chem. Mater, 14, 3964 (2002).

35. T.-H. Lin and K.-C. Ho, Sol. Energy Mater. Sol. Cells, 90, 506 (2006).

36. B. W. Faughnan and R. S. Crandall, in Topics in Applied Physics, Display Devices, J. I. Pankove, Editor, p. 181, Springer-Verlag, New York (1981).

37. M. Lefebvre, Z. Qi, D. Rana, and P. G. Pickup, Chem. Mater, 11, 262 (1999)

38. H. Randriamahazaka, C. Plesse, D. Teyssie, and C. Chevrot, Electrochem. Commun., 542, 33 (2003). 